\title{
Material Too Rigid or Stiff
}

National Cancer Institute

\section{Source}

National Cancer Institute. Material Too Rigid or Stiff. NCI Thesaurus. Code C62847.

Problem associated with an undesired material change in physical property, characterized by rigidity (it resists deformation in response to an applied force). 